\title{
Determinants and impact of suboptimal asthma control in Europe: The INTERNATIONAL CROSS-SECT/ONAL AND LONGTTUDINAL ASSESSMENT ON ASTHMA CONTROL (LIAISON) study
}

Fulvio Braido ${ }^{1}$, Guy Brusselle ${ }^{2,3}$, Daniele Guastalla ${ }^{4}$, Eleonora Ingrassia ${ }^{4^{*}}$, Gabriele Nicolini ${ }^{4}$, David Price ${ }^{5}$, Nicolas Roche 6 , Joan B. Soriano ${ }^{7}$, Heinrich Worth ${ }^{8}$ and on behalf of the LIAISON Study Group

\begin{abstract}
Background: According to the Global Initiative of Asthma, the aim of asthma treatment is to gain and maintain control. In the INTERNATIONAL CROSS-SECTIONAL AND LONGTUUDINAL ASSESSMENT ON ASTHMA CONTROL (LIAISON) study, we evaluated the level of asthma control and quality of life (QoL), as well as their determinants and impact in a population consulting specialist settings.

Methods: LIAISON is a prospective, multicentre, observational study with a cross-sectional and a 12-month longitudinal phase. Adults with an asthma diagnosis since at least 6 months, receiving the same asthma treatment in the 4 weeks before enrolment were included. Asthma control was assessed with the 6-item Asthma Control Questionnaire (ACQ) and QoL with the MiniAsthma Quality of Life Questionnaire (MiniAQLQ).

Results: Overall, 8111 asthmatic patients were enrolled in 12 European countries. Asthma control was suboptimal in $56.5 \%$ of patients and it was associated with poorer asthma-related QoL, higher risk of exacerbations and greater consumption of healthcare resources.

Variables associated with suboptimal control were age, gender, obesity, smoking and comorbidities. Major determinants of poor asthma control were seasonal worsening and persisting exposure to allergens/irritants/ triggers, followed by treatment-related issues.
\end{abstract}

Conclusions: The cross-sectional phase results confirm that suboptimal control is frequent and has a high individual and economic impact.

Trial registration: The clinicaltrials.gov identifier is NCT01567280.

\section{Background}

The main goals of asthma management are to control symptoms, prevent exacerbations, improve and maintain lung function while minimizing side-effects of asthma medications. Improvements in asthma control do not only impact the patients' daily life but are also associated with a reduced risk of exacerbations and lung function impairment. Additionally, gaining and maintaining asthma

\footnotetext{
* Correspondence: e.ingrassia@chiesi.com

${ }^{4}$ Chiesi Farmaceutici S.p.A., Via Palermo 26/A, Parma 43122, Italy

Full list of author information is available at the end of the article
}

control is expected to be cost-effective by reducing the overall cost of asthma care and indirect costs related to decreased productivity. However, in spite of the widespread availability of therapies reported as highly effective in randomised controlled trials [1], variable levels of asthma control have been shown in several "real-life" studies using well-validated self-assessment questionnaires, such as the Asthma Control Questionnaire (ACQ) [2] and the Asthma Control Test (ACT) [3]. In a recent study performed in the Netherlands in 200 adult asthma patients, the percentage of patients with partly controlled or uncontrolled 
asthma was $35.5 \%$ and $27.0 \%$ respectively, as measured by the ACQ [4]. In contrast, observational studies performed in Italy reported about $35 \%$ of suboptimal asthma control $[5,6]$. European-wide, population-based surveys reported prevalence rates of unsatisfactory asthma control levels ranging from $56.6 \%$ [7] to $80.0 \%$ [8, 9].

The discrepancies observed between the results of randomised controlled trials and observational studies are due to the different methodologies applied, the former requiring more restrictive eligibility criteria for the identification of a highly selected population and closer control of single study subjects. In contrast, "real-life" studies comprise larger and more diverse patient populations with/without comorbidities, different levels of treatment adherence and with different approaches in the disease management depending on various factors, like, among others, the qualification of the treating physician, the availability of healthcare resources, or the patient's education to a healthy lifestyle. Moreover, the use of different definitions of asthma control and different tools to measure it makes it difficult to compare different results coming from studies on asthma control [10].

The "INTERNATIONAL CROSS-SECTIONAL AND LONGITUDINAL ASSESSMENT ON ASTHMA CONTROL" (LIAISON) study [11] was carried out to evaluate the determinants and impact of suboptimal asthma control and related quality of life (QoL).

\section{Methods}

\section{Study design}

LIAISON is a multinational, prospective, observational cohort study designed to provide cross-sectional and longitudinal information on asthma control. The study was performed in Austria, Belgium, France, Germany, Greece, Hungary, Italy, the Netherlands, Poland, Spain, Turkey and the United Kingdom and recruited patients between May 2012 and October 2013. In this first report we describe data from the cross-sectional phase of the study, which aimed at evaluating: (i) the proportion of patients with controlled, partly controlled and uncontrolled asthma; (ii) health-related Quality of Life (HRQoL) and its relation to the level of asthma control; and (iii) factors associated with suboptimal asthma control.

The study was conducted in accordance with the current International Conference on Harmonization Good Clinical Practice Guidelines, the World Medical Association Declaration of Helsinki (59th WMA General Assembly, Seoul, October 2008) and all other applicable local laws and regulations. Patients gave written informed consent and study approval was obtained from all relevant local ethics committees and national regulatory authorities.

\section{Study subjects}

Male and female adult patients (smokers and non-smokers) with a GINA-compliant diagnosis of asthma for at least 6 months and treated with the same anti-asthmatic drugs in the last 4 weeks before enrolment were eligible for study participation. Patients suffering from critical conditions and illnesses that might have interfered (according to the doctors' judgment) with the study purposes were excluded.

\section{Collected data and measurements}

The following items were collected and their relations to asthma control were analysed: demographic characteristics (age, gender, body mass index, education level, living environment, employment status, occupational exposure to allergens/irritants/triggers, smoking habits, allergies, concomitant diseases relevant to respiratory tract and outpatients visits), characteristics of asthma (age and severity at diagnosis, qualification of the physician and investigations made for the diagnosis of asthma, current severity of asthma symptoms, need of rescue medication and participation in asthma education programs), the reasons for poor control from the patient's and the physician's perspective (according to their subjective judgment; objective evidence were not required), the anti-asthmatic treatments and the propensity to adhere to therapy.

Self-administered tools were used for the assessment of (i) asthma control (6-item ACQ), (ii) HRQoL (MiniAQLQ) and (iii) propensity to adhere to therapy (4-item Morisky Medication Adherence Scale, MMAS-4).

Number of spirometries, Peak Expiratory Flow (PEF), Forced Expiratory Volume in $1 \mathrm{~s}\left(\mathrm{FEV}_{1}\right)$, Forced Vital Capacity $(\mathrm{FVC})$ and the ratio $\mathrm{FEV}_{1} / \mathrm{FVC}$ values related to the last 12 weeks before the cross-sectional visit, were collected and analysed, when available.

Healthcare resources utilization [emergency room (ER) admittance, hospitalizations, days missed from work due to asthma and support received by family] and severe exacerbations (defined as deterioration of asthma resulting in hospitalization or ER treatment or need of systemic steroids for more than 3 days) in the last 12 months before the cross-sectional visit, were collected and analysed.

\section{Statistical analysis}

The prevalence of patients with controlled, partly controlled and uncontrolled asthma was calculated as the proportion of patients with an ACQ score of $\leq 0.75$, $>0.75-1.5$ and $\geq 1.5$, respectively, over the total of evaluable patients at the cross-sectional phase visit.

Descriptive summary statistics [mean, standard deviation (SD)] were applied for the MiniAQLQ score and other continuous variables. For the ACQ score and other categorical variables, frequencies and percentages were provided. The Kruskal-Wallis test was used to compare 
continuous variables between the different asthma control level groups. For the comparisons of categorical variables, the Chi-square test was performed. The description of the smoking habit considered current smokers, ex-smokers and never-smokers as separate groups of patients.

The sample size was estimated in relation to the expected proportion of patients with controlled asthma at the cross-sectional phase visit (approximately $37.5 \%$ ) [4] and patients with partly controlled/uncontrolled asthma at the cross-sectional phase visit reaching asthma control after 12 months (approximately $45 \%$ ) [12]. Considering a drop-out rate of $20 \%$, an initial patient population of 8150 subjects was calculated in order to have the expected number of 4075 patients evaluable for the assessment of the expected $45 \%$ of patients reaching asthma control at the end of the longitudinal phase with a precision of $\pm 1.5 \%$ [two-sided $95 \%$ confidence interval (CI)].

Considering the expected number of patients reaching asthma control at the end of the longitudinal phase, the distance from the boundaries of the two-sided $95 \%$ CI to the point estimate is 0.055 units for the MiniAQLQ used for the evaluation of QoL, based on a SD of 1.21 units [13].

A multiple logistic regression model was built using stepwise procedures to assess the variables independently associated with asthma control and HRQoL.

\section{Results}

\section{Description of the study population}

Out of 8178 patients attending 153 outpatient hospitals or General Practice clinics, 8111 were considered eligible for the analysis.

The patients' distribution by country in descending order was: Italy $13.6 \%(n=1,101)$, Germany $13.2 \%(n=1,071)$, Spain $12.8 \%(n=1,041)$, Poland $12.8 \%(n=1,037)$, France $10.5 \%(n=854)$, Hungary $10.5 \%(n=851)$, Turkey $5.4 \%$ $(n=439)$, the United Kingdom $4.9 \%(n=399)$, Belgium $4.7 \%(n=382)$, Greece $4.2 \%(n=339)$, Austria $4.0 \%$ $(n=324)$ and the Netherlands $3.4 \%(n=274)$.

Main patients' characteristics are depicted in Table 1.

\section{Asthma control and quality of life}

Among 8111 patients, $43.5 \%(n=3,526)$ showed controlled asthma, $18.0 \%(n=1,462)$ had partly controlled asthma and $38.5 \%(n=3,123)$ uncontrolled asthma. The mean (SD) of ACQ score was 0.27 (0.24), 1.07 (0.19) and $2.48(0.80)$ in patients with controlled, partly controlled and uncontrolled asthma, respectively.

Regarding Asthma Control Index by country, patients in Italy and Spain had greater levels of asthma control, whereas the lowest rates were observed in Hungary, The Netherlands and France (Fig. 1).

Several demographic and clinical differences were observed among patients of the three asthma control levels, especially in the comparison of patients with controlled vs uncontrolled asthma (Table 1).

Table 2 shows the relationship between the study variables and the control of asthma. Obese patients were significantly more likely to have partly controlled/ uncontrolled asthma compared to patients with normal weight. The same was true for female patients vs male patients as well as current smokers vs never-smokers. As regards concomitant diseases, the risk of having partly controlled/uncontrolled asthma was higher for patients reporting respiratory infections, congestive heart failure and psychological disturbances.

Better QoL was reported in patients with controlled asthma and a positive correlation between the level of asthma control and the QoL level was shown (Fig. 2 and Additional file 1: Figure S1, respectively).

A higher score of MiniAQLQ was positively related to younger age (18-39 years) as well as higher age (over 65 years) and male gender, while obesity was negatively related to the MiniAQLQ score. As observed for asthma control, a lower MiniAQLQ score was associated with the presence of congestive heart failure, respiratory infections and psychological disturbances (Table 3).

\section{Characteristics of asthma}

The diagnosis of asthma was made by a respiratory physician in $66.6 \%$ of cases, while the remaining diagnoses were confirmed by general practitioners $(16.9 \%)$ and other, unspecified specialists $(9.5 \%)$. Such information was not available for $7 \%$ of participants. Investigations performed as part of the diagnostic workup included spirometry $(79.8$ $\%$ of patients), allergy tests (53.1\%), chest $\mathrm{x}$-ray (45.8\%), PEF (26.6 \%), IgE measurement (20.7 \%), bronchial provocation (17.1\%) and FENO (5.6\%). Asthma was predominantly persistent at diagnosis $(69.5 \%)$ and was rated severe in $23.6 \%$ of uncontrolled patients (vs $12.7 \%$ among controlled patients).

Daily occurrence of asthma symptoms during the last week before the visit was reported in $37.3 \%$ of uncontrolled patients and need of daily rescue short-acting beta agonist (SABA) use in $34.7 \%$ of uncontrolled patients (vs $2.0 \%$ and $2.7 \%$ of patients with controlled asthma).

The percentage of patients reporting severe exacerbations in the last 12 months before the visit was lower in patients with controlled asthma compared to those with partly controlled $(p=0.019)$ and uncontrolled disease $(p<$ 0.001 ). One severe exacerbation was reported by $8.9 \%$ of controlled-asthma patients and $13.6 \%$ of uncontrolledasthma patients. A higher proportion of uncontrolled patients suffered from more than two severe exacerbations when compared to patients with controlled asthma (6.9\% vs $1.5 \%)$.

We found no difference in the percentage of patients participating in an asthma education program across the 
Table 1 Demographic and clinical characteristics of participants

\begin{tabular}{|c|c|c|c|c|c|}
\hline & $\begin{array}{l}\text { Controlled } \\
n=3526(43.5)\end{array}$ & $\begin{array}{l}\text { Partly controlled } \\
n=1462(18.0)\end{array}$ & $\begin{array}{l}\text { Uncontrolled } \\
n=3123 \text { (38.5) }\end{array}$ & $\begin{array}{l}\text { Overall } \\
p \text {-value* }\end{array}$ & $\begin{array}{l}\text { Overall population } \\
n=8111(100.0)\end{array}$ \\
\hline Age [years], mean (SD) & $49(16)$ & $49(16)$ & $52(15)$ & $<.001$ & $50(16)$ \\
\hline Age categories (years), $n$ (\%) & & & & $<.001$ & \\
\hline$\leq 39$ & $991(30.1)$ & $407(30.0)$ & $572(21.9)$ & & $1970(27.1)$ \\
\hline $40-64$ & $1612(49.0)$ & $694(51.1)$ & $1519(58.2)$ & & $3825(52.7)$ \\
\hline$\geq 65$ & $688(20.9)$ & $257(18.9)$ & $518(19.9)$ & & $1463(20.2)$ \\
\hline \multicolumn{6}{|l|}{ Gender, $n(\%)$} \\
\hline Female & $2207(62.8)$ & $996(68.3)$ & $2184(70.1)$ & $<.001$ & $5387(66.6)$ \\
\hline Body mass index categories, $n(\%)$ & & & & $<.001$ & \\
\hline Normal weight $\left(\geq 18.5\right.$ and $\left.<25 \mathrm{~kg} / \mathrm{m}^{2}\right)$ & $1469(41.7)$ & $545(37.3)$ & $1044(33.4)$ & & $3058(37.7)$ \\
\hline Obese $\left(\geq 30 \mathrm{~kg} / \mathrm{m}^{2}\right)$ & $763(21.7)$ & $384(26.3)$ & $968(31.0)$ & & $2115(26.1)$ \\
\hline Overweight ( $\geq 25$ and $<30 \mathrm{~kg} / \mathrm{m}^{2}$ ) & $1238(35.1)$ & $505(34.5)$ & $1069(34.2)$ & & $2812(34.7)$ \\
\hline Underweight $\left(<18.5 \mathrm{~kg} / \mathrm{m}^{2}\right)$ & $53(1.5)$ & $28(1.9)$ & $42(1.3)$ & & $123(1.5)$ \\
\hline Living environment, $n$ (\%) & & & & 0.038 & \\
\hline Rural & $871(26.8)$ & $412(30.0)$ & $792(27.1)$ & & $2075(27.5)$ \\
\hline Urban & $2374(73.2)$ & $960(70.0)$ & $2131(72.9)$ & & $5465(72.5)$ \\
\hline Education, $n(\%)$ & & & & $<.001$ & \\
\hline None & $54(1.8)$ & $13(1.0)$ & $52(1.9)$ & & $119(1.7)$ \\
\hline Primary/middle school & $1122(36.9)$ & $528(39.9)$ & $1235(45.7)$ & & $2885(40.8)$ \\
\hline High school & 1179 (38.8) & $461(34.8)$ & $890(32.9)$ & & $2530(35.8)$ \\
\hline Graduate/Post Graduate & $685(22.5)$ & $321(24.3)$ & $528(19.5)$ & & $1534(21.7)$ \\
\hline Employment status, $n$ (\%) & & & & $<.001$ & \\
\hline Employed & $1811(56.8)$ & $734(54.0)$ & $1310(45.1)$ & & $3855(51.8)$ \\
\hline Unemployed/housewife/student & $602(18.9)$ & $263(19.3)$ & $553(19.1)$ & & $1418(19.0)$ \\
\hline Retired/Unable to work & $773(24.3)$ & $363(26.7)$ & $1039(35.8)$ & & $2175(29.2)$ \\
\hline Occupational exposure to allergens/irritants among employed, $n(\%)$ & $581(32.1)$ & $294(40.1)$ & $542(41.4)$ & 0.008 & $1417(36.8)$ \\
\hline Smoking habits, $n(\%)$ & & & & $<.001$ & \\
\hline Never-smoker & $2312(66.6)$ & $913(63.8)$ & $1966(63.8)$ & & $5191(65.0)$ \\
\hline Current Smoker & $314(9.0)$ & $182(12.7)$ & $425(13.8)$ & & $921(11.5)$ \\
\hline Ex-Smoker ${ }^{a}$ & $846(24.4)$ & $337(23.5)$ & $691(22.4)$ & & $1874(23.5)$ \\
\hline Smoking history pack years ${ }^{\mathrm{b}}$, mean (SD) & $14(14)$ & $15(14)$ & $16(16)$ & $<.001$ & $15(15)$ \\
\hline Pack years $\geq 10, n(\%)$ & $588(51.9)$ & $280(55.9)$ & $641(58.5)$ & 0.007 & $1509(55.3)$ \\
\hline Allergies, $n(\%)$ & & & & 0.059 & \\
\hline Yes & $2327(68.6)$ & $953(67.3)$ & $1992(65.8)$ & & $5272(67.3)$ \\
\hline No & $1065(31.4)$ & $463(32.7)$ & $1035(34.2)$ & & $2563(32.7)$ \\
\hline \multicolumn{6}{|l|}{ Frequent allergies ${ }^{c}$} \\
\hline Inhalants, $n(\%)$ & $2148(92.3)$ & $861(90.3)$ & $1783(89.5)$ & 0.005 & $4792(90.9)$ \\
\hline Drugs, $n(\%)$ & $247(10.6)$ & $115(12.1)$ & $312(15.7)$ & $<.001$ & $674(12.8)$ \\
\hline Foods, $n(\%)$ & $219(9.4)$ & $98(10.3)$ & $207(10.4)$ & 0.520 & $524(9.9)$ \\
\hline \multicolumn{6}{|l|}{ Comorbidities relevant to respiratory tract ${ }^{d}, n(\%)$} \\
\hline Allergic rhinitis & $976(55.8)$ & $452(57.6)$ & $860(50.3)$ & $<.001$ & $2288(53.9)$ \\
\hline Hypertension & $508(29.0)$ & $247(31.5)$ & $629(36.8)$ & $<.001$ & $1384(32.6)$ \\
\hline Gastro - esophageal reflux & $351(20.1)$ & $181(23.1)$ & $500(29.2)$ & $<.001$ & $1032(24.3)$ \\
\hline Chronic rhinosinusitis & $259(14.8)$ & $96(12.2)$ & $276(16.1)$ & 0.040 & $631(14.9)$ \\
\hline
\end{tabular}


Table 1 Demographic and clinical characteristics of participants (Continued)

\begin{tabular}{|c|c|c|c|c|c|}
\hline Psychological disturbances & $145(8.3)$ & $95(12.1)$ & $333(19.5)$ & $<.001$ & $573(13.5)$ \\
\hline Respiratory infections & $105(6.0)$ & $81(10.3)$ & $288(16.8)$ & $<.001$ & $474(11.2)$ \\
\hline Nasal polyposis & $165(9.4)$ & $54(6.9)$ & $150(8.8)$ & 0.107 & $369(8.7)$ \\
\hline Obstruction Sleep Apnea Syndrome & $74(4.2)$ & $33(4.2)$ & $92(5.4)$ & 0.216 & $199(4.7)$ \\
\hline Congestive heart failure & $27(1.5)$ & $27(3.4)$ & $113(6.6)$ & $<.001$ & $167(3.9)$ \\
\hline \multicolumn{6}{|l|}{ Outpatients visits $^{\mathrm{e}}$} \\
\hline Mean (SD) & $5.3(5.6)$ & $6.9(6.5)$ & $8.3(7.7)$ & $<001$ & $6.7(6.8)$ \\
\hline Patients with at least one visit, $n(\%)$ & $3353(95.1)$ & $1399(95.7)$ & $2996(95.9)$ & 0.241 & $7748(95.5)$ \\
\hline
\end{tabular}

The percentages have been calculated based on the number of available data for each variable $n$ number of patients, $S D$ standard deviation

${ }^{*} p$-value based on Chi-square for categorical variables and Kruskal-Wallis test for quantitative variables

apatients who stopped smoking at least one year prior to study start

${ }^{\mathrm{b}}$ Refers to current smokers and ex-smokers

'The percentages are calculated based on the number of patients with allergies

dPatients could have more than one comorbidity

e Including visits to respiratory physician, allergologist, other specialist and general practitioner in the last 12 months

three groups (Additional file 1: Table S1). By contrast, a difference was detected in investigators' participation in an asthma education program (46.6\% of controlledgroup vs $35.8 \%$ of uncontrolled group).

The percentage of patients who underwent spirometry in the last 12 weeks before the cross-sectional visit was high (73.3\%), and higher in controlled vs uncontrolled patients $(75.0 \%$ vs $70.6 \% ; p<0.001)$. Lung function was poorer in uncontrolled than in controlled patients (Additional file 1: Table S2).

\section{Factors associated with poor control}

The main reasons for poor asthma control were ranked with similar importance by patients and doctors, though with different percentages (multiple answers were permitted). Seasonal worsening and continued exposure to allergens/irritants/triggers were identified most frequently as the main reason for poor control with kappa coefficients indicating a substantial agreement between doctors and patients. Interestingly, active smoking was considered as a possible reason for poor control by only $10.1 \%$ of doctors and $7.4 \%$ of patients.

If the treatment-related aspects (poor adherence, inadequate therapy, poor efficacy, inadequate inhalation technique, poor tolerability) are cumulated, treatment as a whole can be upgraded as the most important factor for poor asthma control representing $60.0 \%$ of the reasons expressed by doctors and $42.7 \%$ of those expressed by patients (Table 4).

\section{Anti-asthma therapies and propensity to adhere}

Fixed combinations of an inhaled corticosteroid (ICS) and a long-acting beta agonist (LABA) were the most frequently used current maintenance anti-asthmatic therapies $(70.5 \%$

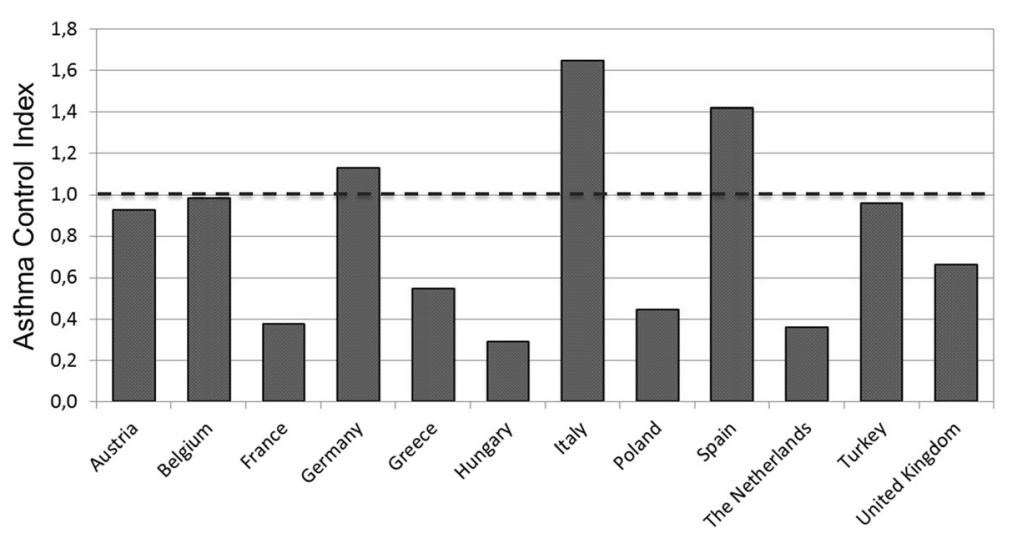

Fig. 1 Asthma Control Index among countries of the LIAISON study. The index was computed as the ratio of patients with controlled asthma (6-item ACQ < 0.75) to patients with not well-controlled asthma (6-item ACQ $\leq 0.75)$. Asthma Control Index >1: greater proportion of patients with controlled asthma. Asthma Control Index <1: greater proportion of patients with not well-controlled asthma 
Table 2 Association between partly controlled/uncontrolled asthma and demographics and comorbid conditions

\begin{tabular}{|c|c|c|c|}
\hline Variable & Odd ratio & $95 \% \mathrm{Cl}$ & $p$-value \\
\hline \multicolumn{4}{|l|}{ Gender } \\
\hline Male vs. Female & 0.7286 & $0.6542,0.8115$ & $<.0001$ \\
\hline \multicolumn{4}{|l|}{ Age [years] } \\
\hline $18-39$ vs. $40-64$ & 0.8563 & $0.7576,0.9678$ & 0.0130 \\
\hline Over 65 vs. $40-64$ & 0.7667 & $0.6707,0.8766$ & 0.0001 \\
\hline \multicolumn{4}{|l|}{ BMI } \\
\hline Overweight vs. Normal weight & 1.2823 & $1.1365,1.4467$ & $<.0001$ \\
\hline Obese vs. Normal weight & 1.7139 & $1.4985,1.9603$ & $<.0001$ \\
\hline \multicolumn{4}{|l|}{ Smoking habits } \\
\hline Current Smoker vs. Never smoker & 1.5852 & $1.3474,1.8649$ & $<.0001$ \\
\hline \multicolumn{4}{|l|}{ Environment } \\
\hline Rural vs. Urban & 1.2419 & $1.1094,1.3902$ & 0.0002 \\
\hline \multicolumn{4}{|l|}{ Gastro-esophageal reflux } \\
\hline Yes vs. no & 1.2480 & $1.0623,1.4661$ & 0.0070 \\
\hline \multicolumn{4}{|l|}{ Psychological disturbances } \\
\hline Yes vs. no & 1.8714 & $1.5087,2.3212$ & $<.0001$ \\
\hline \multicolumn{4}{|l|}{ Respiratory infections } \\
\hline Yes vs. no & 2.4152 & $1.8992,3.0715$ & $<.0001$ \\
\hline \multicolumn{4}{|l|}{ Congestive heart failure } \\
\hline Yes vs. no & 3.4972 & $2.2226,5.5027$ & $<.0001$ \\
\hline
\end{tabular}

$B M I$ body mass index, $\mathrm{Cl}$ confidence interval

The reference group is made of controlled asthmatics. Subjects with available data on variables included in the model were considered $(n=6421)$ Variables included in the logistic regression model were identified after stepwise selection

For each stepwise selection, it was considered 0.05 as significance level for entering and for staying in the model of patients) followed by leukotriene receptor antagonists (24.9\%) and ICS (24.4\%).

Among patients treated with ICS/LABA fixed combinations, $35.0 \%$ were on monotherapy, showing a percentage of patients with controlled asthma of $50.6 \%$.

The mean MMAS-4 score was similar in the three subgroups of patients with an average rating $=1$, corresponding to an intermediate level of treatment adherence. However, a higher rate of low adherence (score 3-4) was present in patients with uncontrolled asthma compared to controlled patients (16.3\% vs $13.0 \%)$. No significant interaction was found between the asthma control level and the nonadherence categories ( $p=0.398$; Additional file 1: Table S3).

\section{Healthcare resource consumption}

The rate of patients who required hospitalization or admitted to an ER was significantly lower in patients with controlled asthma than in those with partly controlled and uncontrolled asthma, even if the total number of events reported in the last 12 months was quite low (4.6 $\%$ of patients were hospitalized and $5.4 \%$ admitted to the ER). Significant differences among the three level of control were detected considering the number of days missed from work and the support received by the family (Additional file 1: Table S4).

Differences between patients with controlled asthma and those not-well controlled are shown by country in Additional file 1: Table S5.

\section{Discussion}

Main findings

The results of the cross-sectional phase of the LIAISON study show that a good control of asthma is achieved in less than $50 \%$ of patients attending specialist settings. Suboptimal control was associated with poorer QoL, a

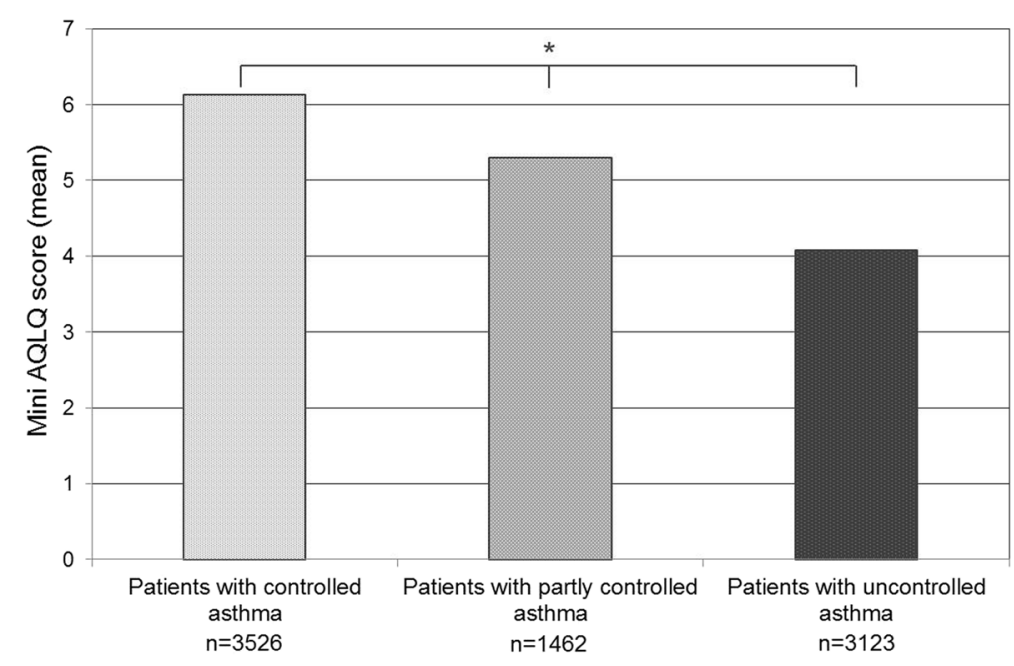

Fig. 2 Mean overall score of the Mini Asthma Quality of Life Questionnaire by asthma control level. *Overall $p$-value $<.001$ 
Table 3 Relationship between quality of life by MiniAQLQ and demographics and comorbid conditions

\begin{tabular}{|c|c|c|c|}
\hline Variable & Beta & $95 \% \mathrm{Cl}$ & $p$-value \\
\hline \multicolumn{4}{|l|}{ Gender } \\
\hline Male vs. Female & 0.2638 & $0.1976,0.3299$ & $<.0001$ \\
\hline \multicolumn{4}{|l|}{ Age [years] } \\
\hline $18-39$ vs. $40-64$ & 0.2786 & $(0.2027,0.3545)$ & $<.0001$ \\
\hline Over 65 vs. 40-64 & 0.1677 & $(0.0861,0.2493)$ & $<.0001$ \\
\hline \multicolumn{4}{|l|}{ BMI } \\
\hline Obese vs. Normal weight & -0.2346 & $(-0.3055,-0.1636)$ & $<.0001$ \\
\hline \multicolumn{4}{|l|}{ Ethnicity } \\
\hline Asian vs. White & -0.8009 & $-1.3949,-0.2069$ & 0.0082 \\
\hline \multicolumn{4}{|l|}{ Smoking habits } \\
\hline Ex-Smoker vs. never-smoker & 0.0991 & $(0.0264,0.1717)$ & 0.0075 \\
\hline \multicolumn{4}{|l|}{ Education } \\
\hline $\begin{array}{l}\text { Graduate/Post Graduate vs. } \\
\text { Primary or middle school }\end{array}$ & 0.3355 & $(0.2520,0.4189)$ & $<.0001$ \\
\hline $\begin{array}{l}\text { High school vs. Primary or } \\
\text { middle school }\end{array}$ & 0.2008 & $(0.1307,0.2708)$ & $<.0001$ \\
\hline \multicolumn{4}{|l|}{ Allergy to Inhalants } \\
\hline Yes vs. no & -0.0942 & $(-0.1597,-0.0288)$ & 0.0048 \\
\hline \multicolumn{4}{|l|}{ Psychological disturbances } \\
\hline Yes vs. no & -0.5340 & $(-0.6497,-0.4184)$ & $<.0001$ \\
\hline \multicolumn{4}{|l|}{ Gastro-esophageal reflux } \\
\hline Yes vs. no & -0.1626 & $(-0.2565,-0.0688)$ & 0.0007 \\
\hline \multicolumn{4}{|l|}{ Respiratory infections } \\
\hline Yes vs. no & -0.5875 & $(-0.7151,-0.4599)$ & $<.0001$ \\
\hline \multicolumn{4}{|l|}{ Congestive heart failure } \\
\hline Yes vs. no & -0.6949 & $(-0.8963,-0.4935)$ & $<.0001$ \\
\hline
\end{tabular}

BMI body mass index, $\mathrm{Cl}$ confidence interval

Subjects with available data on variables included in the model were considered $(n=5618)$

Variables included in the logistic regression model were identified after stepwise selection. For each stepwise selection, it was considered 0.05 as significance level for entering and for staying in the model

higher risk of exacerbations and greater consumption of healthcare resources. Suboptimal control of asthma has also been reported in numerous previous studies $[4,7,8,14,15]$ based on different measures of asthma control, sometimes self-reported by the patient.

Variables associated with control status were age, gender, obesity, smoking, psychological status, history of respiratory infections and congestive heart failure. The same variables were associated with asthma-related QoL, together with education level and allergies. In agreement with previous findings [7], our results confirm that the control of asthma is worse in women than in men, and that the female gender increases the probability of uncontrolled asthma. Moreover, obesity and current smoking were confirmed to be associated with worse control of the disease. In contrast with the same study, our data don't show a relation between increased age and suboptimal control, which may relate to differences in population characteristics (e.g., regarding comorbidities) and care settings (the study by Demoly et al. was based on a selfreported patient database).

\section{General determinants of poor control}

According to patients' and doctors' perspectives, major determinants of poor asthma control were related to environmental aspects followed by treatment-related issues. The main reasons for poor asthma control were reported to be related to seasonal worsening and continued exposure to allergens/irritants/triggers, as well as comorbidities relevant to respiratory tract. Depression, already reported as an independent risk factor for poor asthma control [16], was indicated as a specific reason of uncontrolled asthma in $8.5 \%$ of the LIAISON patients as well as in $9.9 \%$ of doctors. Although about $11.5 \%$ of patients were current smokers, only $7.4 \%$ of patients (and $10.1 \%$ of doctors) considered the active smoking as a possible cause of asthma worsening. Similarly, passive smoking was recognized as a possible reason for poor control by less than $10 \%$ of patients and doctors.

Treatment-related factors are crucial for the control of the disease, representing $60.0 \%$ and $42.6 \%$ of all reasons for poor control (as expressed by doctors and patients, respectively), as a whole. The risk of non-adherence was low in the overall study population as well as in uncontrolled subjects (16.3\%). Two times more physicians than patients identified poor adherence to therapy as a potentially critical factor for poor asthma control, which can relate to different perspectives and understanding about the disease by the patients compared to the physicians [17]. Although patient-physician communication did not seem to represent a discriminant factor for asthma control in our study, good communication is important to establish effective collaboration and helps solving problems of proper inhalation technique like difficulties in device handling $[14,18]$.

These considerations point to the interrelation of various factors impacting on asthma control such as the patients' underestimation of their symptoms [15] and the complexity of disease management in the presence of comorbidities and environmental/seasonal factors.

The fixed combination of inhaled corticosteroids and long-acting beta-agonists was the most widely used therapy in the LIAISON study. Although randomised controlled clinical trials have demonstrated high efficacy and tolerability of the available anti-asthma medications, reallife data like the LIAISON study, still underline that medications alone are not sufficient to obtain control if other factors are not sufficiently taken into consideration such as the understanding of the particular characteristics of 
Table 4 Reasons for poor asthma control, according to patients' and doctors' perspective

\begin{tabular}{|c|c|c|c|}
\hline Reasons for poor control ${ }^{\mathrm{a}}: n=4585$ & $\begin{array}{l}\text { Patients' perspective } \\
n(\%)\end{array}$ & $\begin{array}{l}\text { Doctors' perspective } \\
n(\%)\end{array}$ & Kappa coefficient ${ }^{b}$ \\
\hline $\begin{array}{l}\text { Seasonal worsening } \\
\text { Continued exposure to allergens/irritants/triggers } \\
\text { Comorbidities } \\
\text { Poor adherence to therapy } \\
\text { Inadequate therapy } \\
\text { Poor efficacy of therapy } \\
\text { Active smoking } \\
\text { Depression } \\
\text { Passive smoking } \\
\text { Inadequate inhalation technique } \\
\text { Poor patient-physician communication } \\
\text { Poor tolerability of therapy } \\
\text { Co-administration of drugs } \\
\text { Incorrect diagnosis }\end{array}$ & $\begin{array}{l}1848(40.3) \\
1148(25.0) \\
769(16.8) \\
507(11.1) \\
571(12.5) \\
675(14.7) \\
339(7.4) \\
388(8.5) \\
421(9.2) \\
104(2.3) \\
78(1.7) \\
97(2.1) \\
70(1.5) \\
57(1.2)\end{array}$ & $\begin{array}{l}1756(38.3) \\
1270(27.7) \\
1028(22.4) \\
965(21.0) \\
868(18.9) \\
622(13.6) \\
462(10.1) \\
453(9.9) \\
319(7.0) \\
195(4.3) \\
197(4.3) \\
100(2.2) \\
68(1.5) \\
40(0.9)\end{array}$ & $\begin{array}{l}0.72 \\
0.73 \\
0.68 \\
0.47 \\
0.56 \\
0.53 \\
0.81 \\
0.67 \\
0.64 \\
0.39 \\
0.27 \\
0.44 \\
0.55 \\
0.30\end{array}$ \\
\hline
\end{tabular}

$N$ number of patients

${ }^{a}$ More than one reason could be indicated

${ }^{b}$ Kappa agreement interpretation: <0: poor, 0.01-0.20: slight, $0.21-0.40$ : fair, $0.41-0.60$ : moderate, $0.61-0.80$ : good, $0.81-1.00$; very good

each patient and a careful follow-up of the course of disease.

\section{Impact of poor asthma control}

Importantly, the achievement of good asthma control influences the level of QoL, as shown in our study based on the MiniAQLQ, as well as in other studies using generic QoL tools $[5,19]$. Other studies found that suboptimal control also interacts with activity limitations, work productivity or the frequency of emergency visits $[15,19]$. Previous findings showed that both a history of past asthma exacerbations and poor asthma control can increase the risk of future asthma exacerbations [20, 21]. In this study, we found a difference in severe exacerbations across the asthma control levels but it has to be taken into account that $12.6 \%$ of patients with good asthma control reported a history of severe exacerbation over the previous year. Exacerbations, hospitalizations or ER admittance were lower in controlled patients, confirming the importance of asthma control also in terms of healthcare resource consumption $[5,15,19,22]$. Notably, a greater proportion of controlled patients underwent a spirometry test in the last 12 weeks before the cross-sectional visit as compared to uncontrolled patients.

\section{Strengths and limitations}

The data presented in this manuscript were analysed for the whole study population but what should be taken into account is that the management of patients with asthma as well as the care settings are different among the countries involved in the study. The differences among countries involved is probably reflective of the point of care for patient recruitment i.e., primary or secondary consult. Also, the nature of these consults, whether routine or otherwise.

These populations are not a representative cohort and larger studies are needed to address those factors. The focus of this manuscript is to show the impact of asthma control on individual quality of life as well as healthcare resource utilization.

Some of the data analysed (comorbidities, severe exacerbations, emergency department visits or hospitalizations) were reported by patients and could not be directly verified.

As an additional limitation, some comorbidities such as rhinitis could impact the results. Unfortunately, chronic obstructive pulmonary disease (COPD) was not included in the recorded comorbidities, so it is not possible to exclude that some patients had this concomitant diagnosis.

\section{Conclusion}

The LIAISON study is one of the largest observational studies on characteristics and management of asthmatics in Europe based on patient reported outcomes. The results of the cross-sectional phase confirm that many patients with asthma are not well-controlled in real-life despite the wide availability of highly efficacious treatments. Poorer control of asthma is associated with a worse QoL, an increased risk of exacerbations and more consumption of healthcare resources. Many reasons contribute to poorly controlled asthma, both clinical (i.e., comorbidities) and behavioural (i.e., smoking or non-adherence). Their identification could affect the achievement of asthma control, since most risk factors are modifiable.

Moreover, we expect data analysis of the longitudinal phase of LIAISON; characterizing partly controlled/ uncontrolled asthma over a one-year follow-up in the near future, to be complementary and highly informative.

\section{Additional file}

Additional file 1: Figure S1. Scatter plot of ACQ and miniAQLQ scores. Table S1. Characteristics of asthma. Table S2. Lung function. Table S3. Propensity to adhere to therapy. Table S4. Healthcare resources consumption. Table S5. Healthcare and economic resources consumption by country. (DOCX $155 \mathrm{~kb}$ ) 


\section{Competing interests}

The LIAISON study and the preparation of this manuscript were sponsored by Chiesi Farmaceutici S.p.A.

FB received reports personal fees from THERAMetrics S.p.A. (formerly Pierrel Research Italy SpA) during the conduct of the study; personal fees from AstraZeneca, Biofutura, Boehringer Ingelheim, Chiesi Farmaceutici, Dompè, GlaxoSmithKline, Guidotti, Malesci Menarini, MSD, Mundipharma, Novartis, Takeda, Zambon outside the submitted work.

$\mathrm{GB}$ received fees for advisory boards and lectures from AstraZeneca, Boehringer Ingelheim, Chiesi Farmaceutici, GlaxoSmithKline, Novartis. DG, El and GN are employees of Chiesi Farmaceutici S.p.A.

DP has Board Membership with Aerocrine, Almirall, Amgen, AstraZeneca, Boehringer Ingelheim, Chiesi Farmaceutici, Meda, Mundipharma, Napp, Novartis, and Teva. Consultancy: Almirall, Amgen, AstraZeneca, Boehringer Ingelheim, Chiesi Farmaceutici, GlaxoSmithKline, Meda, Mundipharma, Napp, Novartis, Pfizer, and Teva; Grants and unrestricted funding for investigatorinitiated studies from UK National Health Service, British Lung Foundation, Aerocrine, AKL Ltd, Almirall, AstraZeneca, Boehringer Ingelheim, Chiesi Farmaceutici, Eli Lilly, GlaxoSmithKline, Meda, Merck, Mundipharma, Napp, Novartis, Orion, Pfizer, Respiratory Effectiveness Group, Takeda, Teva, and Zentiva; Payments for lectures/speaking: Almirall, AstraZeneca, Boehringer Ingelheim, Chiesi Farmaceutici, Cipla, GlaxoSmithKline, Kyorin, Meda, Merck, Mundipharma, Novartis, Pfizer, SkyePharma, Takeda and Teva; Payment for manuscript preparation: Mundipharma and Teva; Patents (planned, pending or issued): AKL Ltd.; Payment for the development of educational materials: GlaxoSmithKline, Novartis; Stock/Stock options: Shares in AKL Ltd which produces phytopharmaceuticals and owns $80 \%$ of Research in Real Life Ltd and its subsidiary social enterprise Optimum Patient Care; received Payment for travel/accommodations/meeting expenses from Aerocrine, Boehringer Ingelheim, Mundipharma, Napp, Novartis, and Teva; Funding for patient enrolment or completion of research: Almirral, Chiesi Farmaceutici, Teva, and Zentiva; and Peer reviewer for grant committees: Medical Research Council (2014), Efficacy and Mechanism Evaluation programme (2012), HTA (2014). JS received consulting fee/honorarium from Chiesi Farmaceutici NR has received over the past 3 years (i) fees for speaking, organising education, participation in advisory boards or consulting from Aerocrine, Almirall, AstraZeneca, Boehringer Ingelheim, Chiesi Farmaceutici, Cipla, GlaxoSmithKline, MSD-Chibret, Mundipharma, Novartis, Pfizer, Stallergenes, Takeda, Teva; (ii) research grants from Novartis, Boehringer Ingelheim and Pfizer.

HW received personal fees from AstraZeneca, Boehringer Ingelheim, Chiesi Farmaceutici, GlaxoSmithKline, Klosterfrau, Menarini, Novartis, Takeda.

\section{Authors' contributions}

All authors contributed to the study conception and design and were responsible for the drafting, review and final approval of the manuscript.

\section{Acknowledgements}

We are grateful to THERAmetrics for the study management, data collection and analysis.

The authors would like to thank the following investigators for their contribution (>30 patients enrolled): F. Fohler, A.G. Haider, J. Hesse-Tonsa, J. Messner, W. Pohl (Austria); G. Joos, J.L. Halloy, R. Peche, H. Simonis, P. Van den Brande (Belgium); B. Bugnas, J.M. Chavaillon, P. Debove, S. Dury, L. Mathieu, O. Lagrange, A. Prudhomme, S. Verdier (France); A. Benedix, O. Kestermann, A. Deimling, G. Eckhardt, M. Gernhold, V. Grimm-Sachs, M. Hoefer, G. Hoheisel, C. Stolpe, C. Schilder, M. John, J. Uerscheln, K.H. Zeisler (Germany); A. Chaniotou, P. Demertzis, V. Filaditaki-Loverdou, A. Gaga, E. Georgatou-Papageorgiou, S. Michailidis, G. Pavkalou, M. Toumpis (Greece); K. Csicsari, K. Hajdu, M. Póczi, M. Kukuly, T. Kecskes, C. Hangonyi, J. Schlezak, E. Takács, M. Szabo,G. Szabó, C. Szabo (Hungary); G.W. Canonica, W. Castellani, A. Cirillo, M.P. Foschino Barbaro, M. Gjomarkaj, G. Guerra, G. Idotta, D. Legnani, M. Lo Schiavo, R. Maselli, F. Mazza, S. Nutini, P. Paggiaro, A. Pietra, O. Resta, S. Salis, N.A. Scichilone, M.C. Zappa, A. Zedda (Italy); M. Goosens, R. Heller, K. Mansour, C. Meek, J. van den Berg (The Netherlands); A. Antczak, M. Faber, D. Madra-Rogacka, G. Mincewicz, M. Michnar, D. Olejniczak, G. Pulka, Z. Sankowski, K. Kowal, I. Krupa-Borek, B. Kubicka Kozik, K. Kuczynska, P. Kuna, A. Kwasniewski, M. Wozniak (Poland); F. Casas Maldonado, C. Cisneros, J. de Miguel Díez, L.M. Entrenas Costa, B. Garcì-Cosio, M.V. Gonzales, L. Lores, M. Luengo, C. Martinez, C. Melero, I. Mir, X. Munoz, A. Pacheco, V. Plaza, J. Serra, J. Serrano, J.G. Soto Campos (Spain); T. Bekci, R. Demir, N. Dursunoglu, D. Ediger,
A. Ekici, O. Goksel, H. Gunen, I.K. Oguzulgen, Z.F. Ozseker, (Turkey); L. Barnes, T. Hall, S. Montgomerie, J. Purohit, J. Ryan (United Kingdom). The authors would also like to thank P. Galletti (THERAMetrics S.p.A., Sesto San Giovanni, Italy) and K. Stockmeyer (THERAMetrics GmbH, Essen, Germany) for providing editorial assistance in the preparation of this manuscript.

\section{Author details}

${ }^{1}$ Allergy and Respiratory Diseases Clinic, University of Genoa, IRCCS-AOU San Martino, Genoa, Italy. '2Department of Respiratory Medicine, Ghent University Hospital, Ghent, Belgium. ${ }^{3}$ Departments of Epidemiology and Respiratory Medicine, Erasmus MC, Rotterdam, The Netherlands. ${ }^{4}$ Chiesi Farmaceutici S.p.A., Via Palermo 26/A, Parma 43122, Italy. ${ }^{5}$ Centre of Academic Primary Care, University of Aberdeen, Aberdeen, UK. ${ }^{6}$ Service de Pneumologie et Réanimation, Hôtel-Dieu, Groupe Hospitalier Cochin-Broca-Hôtel-Dieu, Assistance Publique-Hôpitaux de Paris, Université Paris Descartes, Paris, France. ${ }^{7}$ Instituto de Investigación Hospital Universitario de la Princesa (IISP), Universidad Autónonoma de Madrid, Madrid, Spain. ${ }^{8}$ Facharztforum Fürth, Fürth, Germany.

\section{Received: 2 December 2015 Accepted: 4 May 2016}

Published online: 14 May 2016

\section{References}

1. Bateman ED, Boushey HA, Bousquet J, Busse WW, Clark TJ, Pauwels RA, Pedersen SE, GOAL Investigators Group. Can guideline-defined asthma control be achieved? The Gaining Optimal Asthma Control study. Am J Respir Crit Care Med. 2004;170:836-44.

2. Juniper EF, O'Byrne PM, Guyatt GH, Ferrie PJ, King DR. Development and validation of a questionnaire to measure asthma control. Eur Respir J. 1999;14:902-7.

3. Nathan RA, Sorkness CA, Kosinski M, Schatz M, Li JT, Marcus P, Murray JJ, Pendergraft TB. Development of the asthma control test: a survey for assessing asthma control. J Allergy Clin Immunol. 2004;113:59-65.

4. Van der Meer V, van Stel HF, Bakker MJ, Roldaan AC, Assendelft WJ, Sterk PJ, Rabe KF, Sont JK, SMASHING (Self-Management of Asthma Supported by Hospitals, ICT, Nurses and General practitioners) Study Group. Weekly self-monitoring and treatment adjustment benefit patients with partly controlled and uncontrolled asthma: an analysis of the SMASHING study. Respir Res. 2010;11:74.

5. Allegra L, Cremonesi G, Girbino G, Ingrassia E, Marsico S, Nicolini G, Terzano C, PRISMA (PRospectlve Study on asthMA control) Study Group. Real-life prospective study on asthma control in Italy: cross-sectional phase results. Respir Med. 2012;106:205-14.

6. Bettoncelli G, Magnoni MS, Fassari C, Tosatto R, Di Blasi P, De Marco R, Novelletto BF, Mazzaglia GP, Caramori G, Studio P.A.C.I.S. (Point out Asthma Control Italian Survey). II controllo dell'asma in Italia misurato con ACT (Asthma Control Test). Società Italiana di Medicina Generale. 2006;6:10-7.

7. Demoly P, Gueron B, Annunziata K, Adamek L, Walters RD. Update on asthma control in five European countries: results of a 2008 survey. Eur Respir Rev. 2010;19:150-7.

8. Cazzoletti L, Marcon A, Janson C, Corsico A, Jarvis D, Pin I, Accordini S, Almar E, Bugiani M, Carolei A, Cerveri I, Duran-Tauleria E, Gislason D, Gulsvik A, Jõgi R, Marinoni A, Martínez-Moratalla J, Vermeire P, de Marco R, Therapy and Health Economics Group of the European Community Respiratory Health Survey. Asthma control in Europe: a real-world evaluation based on an international population-based study. J Allergy Clin Immunol. 2007;120:1360-7.

9. iHARP: initiative Helping Asthma in Real-life Patients. http://iharp.org/. (accessed 3 March 2013).

10. Roche N, Reddel HK, Agusti A, Bateman ED, Krishnan JA, Martin RJ, Papi A Postma D, Thomas M, Brusselle G, Israel E, Rand C, Chisholm A, Price D. Integrating real-life studies in the global therapeutic research framework. Lancet Respir Med. 2013;1:30-2.

11. Braido F, Brusselle G, Ingrassia E, Nicolini G, Price D, Roche N, Soriano JB, Worth H, LIAISON study group. InternationaL cross-sectlonAl and longltudinal assessment on aSthma cONtrol in European adult patients-the LIAISON study protocol. BMC Pulm Med. 2013;13:18.

12. O'Byrne PM, Reddel HK, Eriksson G, Ostlund O, Peterson S, Sears MR, Jenkins C, Humbert M, Buhl R, Harrison TW, Quirce S, Bateman ED. 
Measuring asthma control: a comparison of three classification systems. Eur Respir J. 2010;36:269-76.

13. Ehrs PO, Nokela M, Ställberg B, Hjemdahl P, Wikström Jonsson E. Brief questionnaires for patient-reported outcomes in asthma: validation and usefulness in a primary care setting. Chest. 2006;129:925-32.

14. Price $\mathrm{D}$, Fletcher $\mathrm{M}$, van der Molen $\mathrm{T}$. Asthma control and management in 8,000 European patients: the REcognise Asthma and LInk to Symptoms and Experience (REALISE) survey. Primary Care Respiratory Medicine. 2014;24:14009.

15. Rabe KF, Vermeire PA, Soriano JB, et al. Clinical management of asthma in 1999: the Asthma Insights and Reality in Europe (AIRE) study. Eur Respir J. 2000;16:802-7.

16. Fernandes L, Fonseca J, Martins S, et al. Association of anxiety with asthma: subjective and objective outcome measures. Psychosomatics. 2010;51:39-46.

17. Soriano JB, Rabe KF, Vermeire PA. Predictors of poor asthma control in European adults. J Asthma. 2003;40:803-13.

18. Hardwell A, Barber V, Hargadon T, McKnight E, Holmes J, Levy ML. Technique training does not improve the ability of most patients to use pressurised metered dose inhalers (pMDIs). Prim Care Respir J. 2011;20:92-6.

19. Demoly P, Annunziata K, Gubba E, Adamek L. Repeated cross-sectional survey of patient reported asthma control in Europe in the past 5 years. Eur Respir Rev. 2012;21(123):66-74.

20. Peters D, Chen C, Markson LE, Allen-Ramey FC, Vollmer WM. Using an asthma control questionnaire and administrative data to predict health-care utilization. Chest. 2006;129:918-24.

21. Price D, Wilson M, Chisholm A, Rigazio A, Burden A, Thomas M, King C. Predicting frequent asthma exacerbations using blood eosinophil count and other patient data routinely available in clinical practice. J Asthma Allergy. 2016;9:1-12.

22. Holgate ST, Price D, Valovirta E. Asthma out of control? A structured review of recent patient surveys. BMC Pulm Med. 2006;6 Suppl 1:s2.

\section{Submit your next manuscript to BioMed Central and we will help you at every step:}

- We accept pre-submission inquiries

- Our selector tool helps you to find the most relevant journal

- We provide round the clock customer support

- Convenient online submission

- Thorough peer review

- Inclusion in PubMed and all major indexing services

- Maximum visibility for your research

Submit your manuscript at www.biomedcentral.com/submit 